\title{
Cortical Excitability in Amyotrophic Lateral Sclerosis: A Clue to Pathogenesis
}

\author{
Andrew Eisen, Bhanu Pant and Heather Stewart
}

\begin{abstract}
Motor evoked potentials (MEPs) were recorded from selected non-wasted, non-denervated hand muscles in 40 patients with Amyotrophic Lateral Sclerosis (ALS) with both upper and lower motor neuron signs. In most the compound muscle action potential (CMAP) of the target muscle was normal. Compared to the control group, cortical threshold in ALS varied considerably and there was a significant $\left(r^{2}=0.702\right)$ inverse, exponential, correlation between cortical threshold and MEP/CMAP ratio. There was a linear correlation between threshold and disease duration $\left(r^{2}=0.66\right)$ so that early in the disease threshold was normal and later the motor cortex could not be stimulated. It is suggested that early in ALS normal threshold reflects glutamate-induced hyper-excitability of the corticomotoneuron. The findings lend support to the hypothesis that ALS is primarily a disease of the corticomotoneuron.
\end{abstract}

RÉSUMÉ: Excitabilite corticale dans la sclérose latérale amyotrophique: un indice de sa pathogenèse. Nous avons enregistré les potentiels évoqués moteurs (PEM) de muscles de la main non-atrophiés et non-dénervés chez 40 patients atteints de sclérose latérale amyotrophique (SLA) ayant des signes d'atteinte du neurone moteur central et periphérique. Chez la plupart, le potentiel d'action musculaire composé (PAMC) du muscle cible était normal. Comparé au groupe contrôle, le seuil cortical variait considérablement dans la SLA et il existait une corrélation inverse significative $\left(r^{2}=0.702\right)$, exponentielle, entre le seuil cortical et le rapport PEM/PAMC. Il existait une corrélation linéaire entre le seuil et la durée de la maladie $\left(r^{2}=0.66\right)$, de telle sorte que le seuil était normal au début de la maladie et par la suite, le cortex moteur ne pouvait plus être stimulé. Nous suggérons que, tôt dans la SLA, le seuil normal reflète l'hyperexcitabilité du neurone moteur cortical induite par le glutamate. Ces observations supportent l'hypothèse que la SLA est avant tout une maladie du neurone moteur cortical.

Can. J. Neurol. Sci. 1993; 20:11-16

Transcranial magnetic stimulation excites the cortico-spinal tracts transsynaptically, activating the fast conducting corticomotoneurons, ${ }^{2,3}$ which connect monosynaptically with the anterior horn cells. The corticomotoneuronal system is well developed in primates and particularly so in humans. ${ }^{4.5}$ This system is largely responsible for the highly fractionated movements that primates enjoy. Connections are most abundant to the hand motor neuron pool; ${ }^{6.7}$ but in humans they have been demonstrated to all motor neuron pools except those innervating the external ocular muscles and bladder, which are typically spared in Amyotrophic Lateral Sclerosis (ALS). ${ }^{8}$

This anatomical arrangement in humans and the lack of a natural or, thus far, induced animal model that truly mimics $\mathrm{ALS}^{9}$ and the primitive nature of the corticomotoneuronal system in non-primates, has led to the hypothesis that disease of the corticomotoneuron is the initial event in ALS and that demise of the anterior horn cell is secondary to anterograde effects. ${ }^{10.11}$ Charcot ${ }^{12}$ had a similar concept of ALS over a century ago.

Anatomical proof for this hypothesis requires demonstration of degeneration in parts of the primary motor area connected with spinal segments in which the motor neurons were unaffected at the time of death and coincident degeneration of those corticomotoneurons connected to already degenerated anterior horn cells. ${ }^{13}$ Pathological proof is probably not possible, since there is not a one to one relationship between the corticomotoneuron and the anterior horn cell. Each anterior horn cell receives input from several, maybe many, corticomotoneurons and one corticomotoneuron makes monosynaptic connections with anterior horn cells of its own muscle as well as agonists and even antagonists. ${ }^{14-16}$ The anatomic relation is further frought with difficulty because anterior horn cells "overloaded" as a result of sprouting initiate their own effects at a spinal level. As a result, quantitative comparison of loss of corticomotoneurons versus anterior horn cells would be difficult, if not impossible, to evaluate after death.

A different approach is through the use of transcranial magnetic stimulation. This, together with conventional studies used to evaluate the peripheral nervous system, may enable one to demonstrate evidence for early corticomotoneuronal versus anterior horn cell disease.

Central motor conduction and motor evoked potential (MEP) latency are frequently normal in ALS even in the presence of

From the Neuromuscular Diseases Unit, The Vancouver General Hospital and The University of British Columbia, Vancouver Received July 15, 1992. Accepted September 25, 1992

Reprint requests to: Dr. A. Eisen, The Neuromuscular Diseases Unit, The Vancouver General Hospital, 855 West 12th Avenue, Vancouver, British Columbia, Canada V5Z $1 \mathrm{M} 9$ 
motor deficit affecting fine finger movement. ${ }^{17}$ Here we report changes in the threshold to cortical stimulation and the ratio of the MEP to the compound muscle action potential (CMAP), both of which are measures of the integrity of the corticomotoneuron.

\section{METHODS}

\section{Subjects}

Forty patients with ALS gave informed consent for investigation. The majority were studied within 15 months (range 3 30 months) of onset of their disease, timed from initial symptoms. Their mean age was $57.9 \pm 12.4$ years; there were 21 men. The protocol employed was approved by the Human Ethics Committee of the University of British Columbia.

A diagnosis of ALS was based upon the neurological history and examination and laboratory tests. ${ }^{18}$ Patients were included if: 1. There was a history of progressive asymmetrical muscle weakness over weeks or months. 2 . There was clinical evidence of both upper and lower motor neuron dysfunction in the face of normal eye movements, sphincter function and sensory examination. 3. Absence of significant motor or sensory conduction abnormalities or motoneuronopathy with multifocal motor conduction block. ${ }^{19,20}$ 4. Electrophysiological evidence of anterior horn cell disease ${ }^{21}$ and 5. Normal imaging (CT and/or MRI) of the brain and spinal cord.

Patients with purely progressive muscular atrophy, previous poliomyelitis or postpoliomyelitis syndrome, primary lateral sclerosis, monomelic amyotrophy and a family history of ALS were excluded and patients who had multifocal motor conduction block. Also excluded were patients with severe systemic disease occurring within 2 years of developing symptoms of ALS.

Thirty-five subjects, without neurological or other disease, matched for age, were also studied.

\section{Magnetic Stimulation}

Motor evoked potentials (MEPs) were elicited by transcranial magnetic stimulation using a Dantec circular coil, with an outer diameter of $10.5 \mathrm{~cm}$ and a $6.5 \mathrm{~cm}$ central hole. The subject was seated comfortably in a temperature-maintained environment $\left(20-22^{\circ} \mathrm{C}\right)$. Electromyographic responses were recorded from the either thenar or hypothenar muscles employing surface electrodes filled with electrogel. The $G_{1}$ electrode was placed over the muscle belly endplate and the the $G_{2}$ electrode over the distal tendinous insertion. MEPs were recorded from whichever of the 4 selected muscles had the largest compound muscle action potential (CMAP). No attempt was made to record MEPs from muscles that were severely wasted or which demonstrated marked evidence of denervation (fibrillation of positive sharp waves).

MEPs were elicited with the muscle at rest. The coil was placed flat over the vertex but moved as neccessary to obtain optimal responses. ${ }^{22}$ Audio feedback was used to ensure lack of voluntary muscle activity during cortical stimulation. Relaxation was defined as the absence of EMG activity at a display gain of $20 \mu \mathrm{V} /$ division. In the event that the target muscle was fasciculating, care was taken to deliver the cortical stimulus in a fasciculation-free period. Ten to twenty responses were obtained and the ones with the shortest onset latency and largest peak to peak amplitude were measured. The output of the stimulator was $25 \%-30 \%$ above threshold.

Threshold is a measure of excitation of the corticomotoneuron and is defined as the strength or output of the stimulator, expressed as the percentage, required to elicit a potential of $>20 \mu \mathrm{V}$ amplitude in 3 out of 5 consecutive trials of stimulation with the coil in the optimal position. ${ }^{23-25}$ Threshold measurements were excluded from the ALS data if a spontaneous fasciculation coincided with the magnetic stimulus.

The MEP/CMAP ratio was measured by dividing the maximum amplitude compound muscle action potential (CMAP) elicited by supramaximal electrical stimulation of the median or ulnar nerves at the wrist into the largest cortically evoked response. Central motor delay (CCT) was derived from the latency difference of the MEPs elicited by placing the coil over the cortex and the lower cervical spine in the midline (Eisen and Shytbel 1990).

Potentials were considered abnormal if any of the following pertained: absent response, latency $\geq 25.0 \mathrm{msec}$, CCT $\geq 11.5$ msec, MEP amplitude $\leq 1.2 \mathrm{mV}$, MEP/CMAP ratio $\leq 10 \%$, threshold $\geq 67.5 \%$. A CMAP of $\leq 6.9 \mathrm{mV}$ was also considered abnormal.

\section{RESULTS}

Duration of disease, determined from the onset of initial symptoms, ranged from $3-30$ months (mean $=8.35 \pm 7.6$ months). In $14(35 \%)$ of cases the initial symptoms were bulbar in nature. There was no significant correlation between any of the MEP abnormalities and, either general clinical deficit (i.e., bulbar versus non-bulbar predominance, marked spasticity or very brisk reflexes) or focal hand neurological deficit (i.e., difficulty with fine finger movements or brisk finger flexion).

Individual patient values for latency, motor evoked potential (MEP) amplitude, compound muscle action potential amplitude (CMAP), MEP/CMAP ratio and cortical threshold are plotted in Figure 1. The upper or lower normal limits, indicated by the arrows, were derived from the aged-matched control group. The frequency of abnormalities for each measurement is given in Table 1. Mean group latency and central motor conduction time were modestly but significantly prolonged compared to the aged-matched control group (see Table 1). There was no difference in the patient and control CMAPs and only 7 patients had a CMAP that was below normal. However, the cortically evoked motor potential (MEP) amplitude and MEP/CMAP ratio were significantly reduced in the patients.

Values for cortical threshold in the normal subjects fell within a fairly narrow range and there was no relation between it and MEP/CMAP ratio (see Figure 2A). This contrasted with the wide range of threshold in patients with ALS. Three had thresholds lower than the lowest recorded in the control group and in 9 patients $(22.5 \%)$ it was not possible to elicit a potential even at maximum output of the stimulator. In the ALS patients there was a highly significant $\left(r^{2}=0.702\right)$, exponential $\left(y=a x^{b}\right)$, relationship between cortical threshold and MEP/CMAP ratio (Figure 2B) but not between cortical threshold and MEP amplitude (Figure 3).

There was also a significant positive linear correlation $\left(\mathrm{r}^{2}=\right.$ 0.658 ) between cortical threshold and disease duration (Figure 4). 


\section{Discussion}

Earlier studies in ALS used electrical stimulation of the motor cortex and showed that there was a modest prolongation of central motor conduction time and frequently marked attenuation or in some cases absence of the MEP. ${ }^{26.27}$ Schriefer et al. ${ }^{28}$ studied 22 ALS patients using transcranial magnetic stimulation and found only a weak correlation between central motor conduction prolongation and other MEP abnormalities and hyperreflexia of the limb studied including brisk finger flexion. There

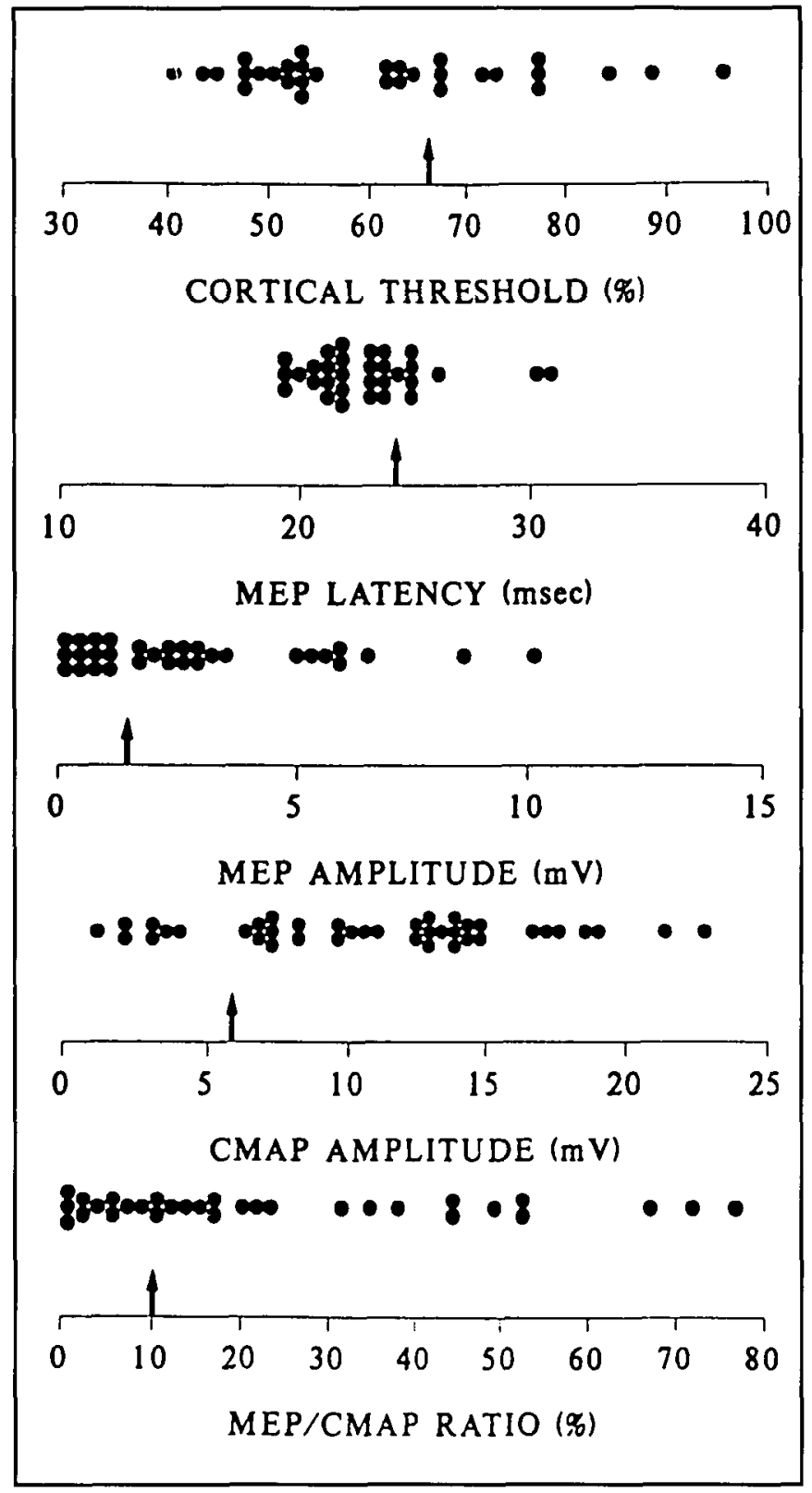

Figure I - Scatterplots for different motor evoked potential (MEP) characteristics in 40 parients with ALS. No response was obtained in 9 patients. The hypothenar compound muscle action potential amplinde (CMAP) is also shown. The arrows indicate the upper (for threshold. latency) and lower (for MEP and CMAP amplitudes and MEPICMAP ratio) normal limits. The normal limits which were derived from the control group are 2.5 SD above or below' the normal mean. was no correlation between central motor conduction and impairment of fine finger movement or hypothenar muscle weakness. Abnormal MEPs were also recorded in some patients with a normal clinical examination of the limb studied and normal MEPs were recorded in 5 cases who had definite neurological deficit. Subsequently, Eisen et al. ${ }^{29}$ recording from several upper limb muscles, found that an absent MEP was most frequent in patients with severe bulbar features.

Recent reports indicate that prolongation of central conduction in ALS is more likely to be detected by electrical rather than magnetic stimulation, ${ }^{30}$ but that a reduced MEP/CMAP ratio is the commonest abnormality with magnetic stimulation. In the present study MEP amplitude, MEP/CMAP ratio and cortical threshold were abnormal in about $50 \%$ of the patients. The frequency of these abnormalities in combination approached $75 \%$. Latency or central motor delay were abnormal with a much lower frequency and were never abnormal if the other MEP characteristics were normal.

The majority of our patients were seen early in the course of their disease and most were ambulatory. We found no correlation between severity or type of motor deficit and electrophysiological abnormalities.

Factors determining the MEP/CMAP ratio and cortical threshold in ALS, a disease affecting both the corticomotoneuron and the anterior horn cell, are complex and interactive. Assuming an optimal coil position, they include: 1. Survival or demise of the corticomotoneuron relative to the anterior horn cell (i.e., the number of functioning corticomotoneuronal connections). 2. The number, size and synchrony of descending volleys initiated by the stimulus and their ability to raise the anterior horn cell to threshold. ${ }^{31} 3$. The cell membrane properties of both the corticomotoneuron and the anterior horn cell. 4. Modifying central and peripheral, excitatory or inhibitory influences, such as spasticity.

Table 1: Motor Evoked Potential Measurements in ALS

\begin{tabular}{|c|c|c|c|}
\hline & Normal $(n=35)$ & $\operatorname{ALS}(n=40)$ & p Value \\
\hline AGE & $56.2 \pm 13.4$ & $57.9 \pm 12.4$ & NS \\
\hline THRESHOLD (\%) & $54.8 \pm 5.1$ & $\begin{array}{c}63.6 \pm 8.2 \\
\text { (17 abnormal) }\end{array}$ & NS \\
\hline LATENCY (msec) & $21.2 \pm 1.5$ & $\begin{array}{c}23.0 \pm 2.8 \\
(15 \text { abnormal })\end{array}$ & $<0.02$ \\
\hline MEP AMPLITUDE (mV) & $4.9 \pm 4.6$ & $\begin{array}{c}2.8 \pm 2.6 \\
(20 \text { abnormal) }\end{array}$ & $<0.01$ \\
\hline $\mathrm{CMAP}(\mathrm{mV})$ & $13.8 \pm 4.3$ & $\begin{array}{c}11.7 \pm 5.7 \\
\text { (7 abnormal) }\end{array}$ & NS \\
\hline MEP/CMAP RATIO (\%) & $35.5 \pm 17.4$ & $\begin{array}{c}21.9 \pm 21.3 \\
\text { (18 abnormal) }\end{array}$ & $<0.02$ \\
\hline CMCT & $7.8 \pm 1.5$ & $\begin{array}{c}10.5 \pm 1.9 \\
(15 \text { abnormal) }\end{array}$ & $<0.01$ \\
\hline
\end{tabular}

(Values are the mean \pm one standard deviation).

MEPs were recorded from the resting thenar or hypothenar muscles. CMAP $=$ compound muscle action potential. $\mathrm{CMCT}=$ central motor conduction time. Threshold is defined as the output $(\%)$ needed to elicit a potential of $\geq 20 \mu \mathrm{V}$ in $3 / 5$ consecutive trials. The number of patients with an abnormality of each measurement is given below the mean. For MEP measurements this number includes 9 patients with absent responses. 
The above factors are largely difficult, or impossible, to control. Nevertheless, MEPs were selectively recorded from nonwasted, non-denervated hand muscles, indicated by the absence of fibrillation or positive sharp waves, associated with a normal CMAP amplitude in more than $80 \%$ of the patients. Under these

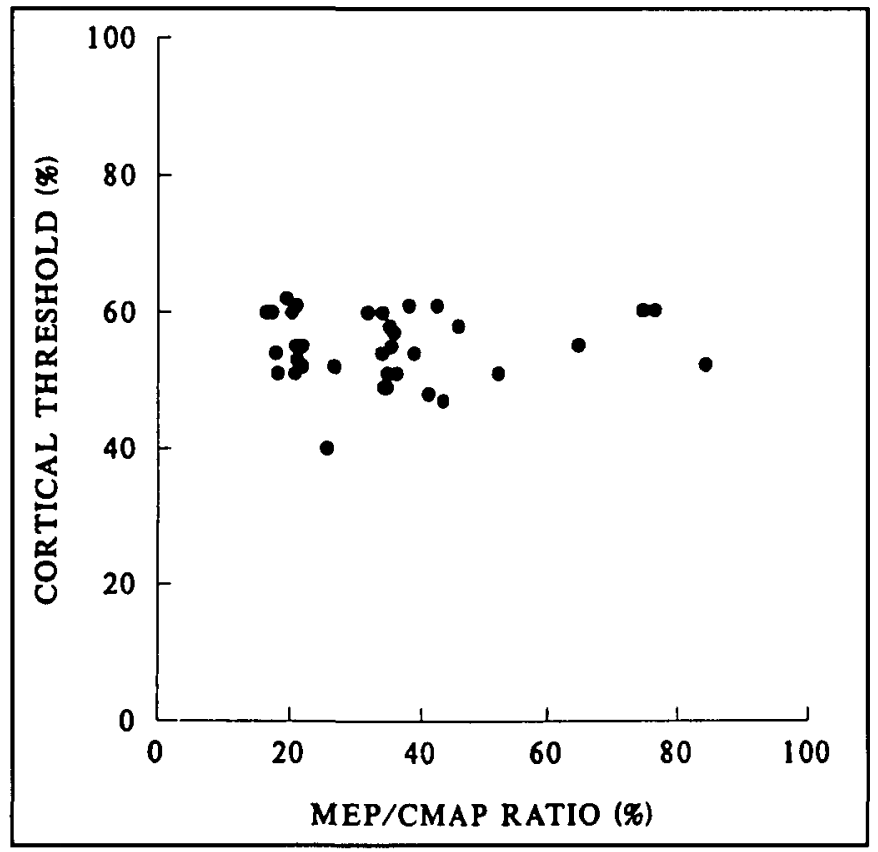

A circumstances it is reasonable to conclude that reduction in the MEP/CMAP ratio was due primarily to corticomotoneuronal rather than anterior horn cell disease or demise. This view is supported by the significant relationship between MEP/CMAP ratio and cortical threshold (Figure $2 \mathrm{~A}$ ) and the absence of any

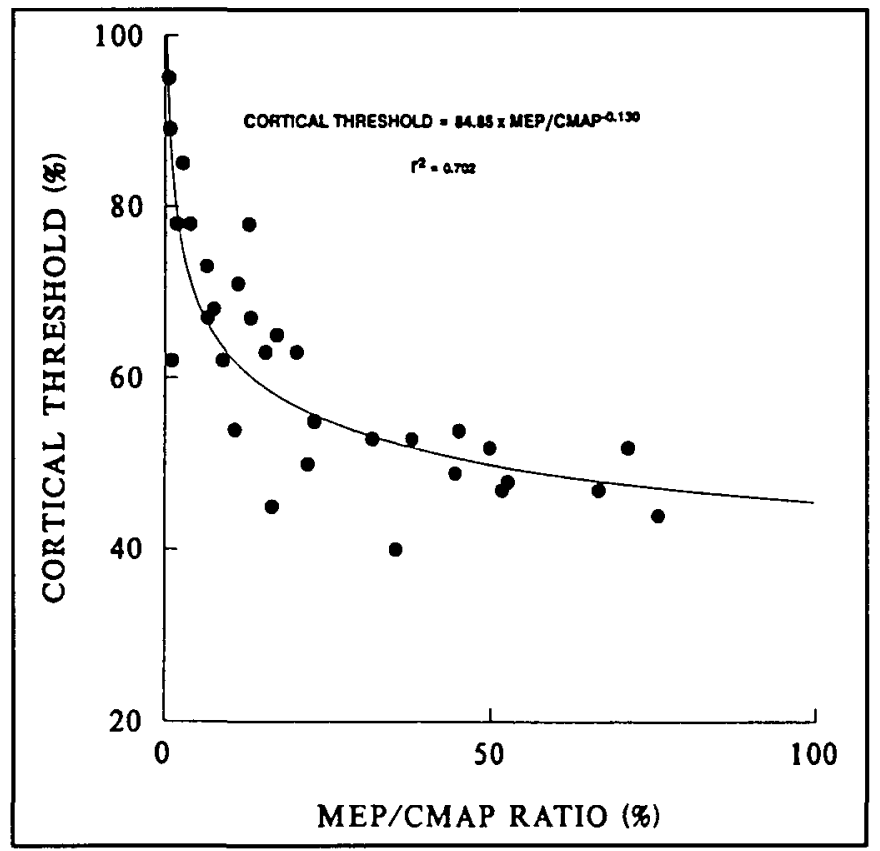

B

Figure 2 - A. In normal subjects values for cortical threshold are clustered and show no particular relation to cortical threshold. B. Relationship between threshold to cortical stimulation in ALS and MEP/CMAP ratio. The power curve shown and given by $Y=a X^{b}$ best fitted the data.

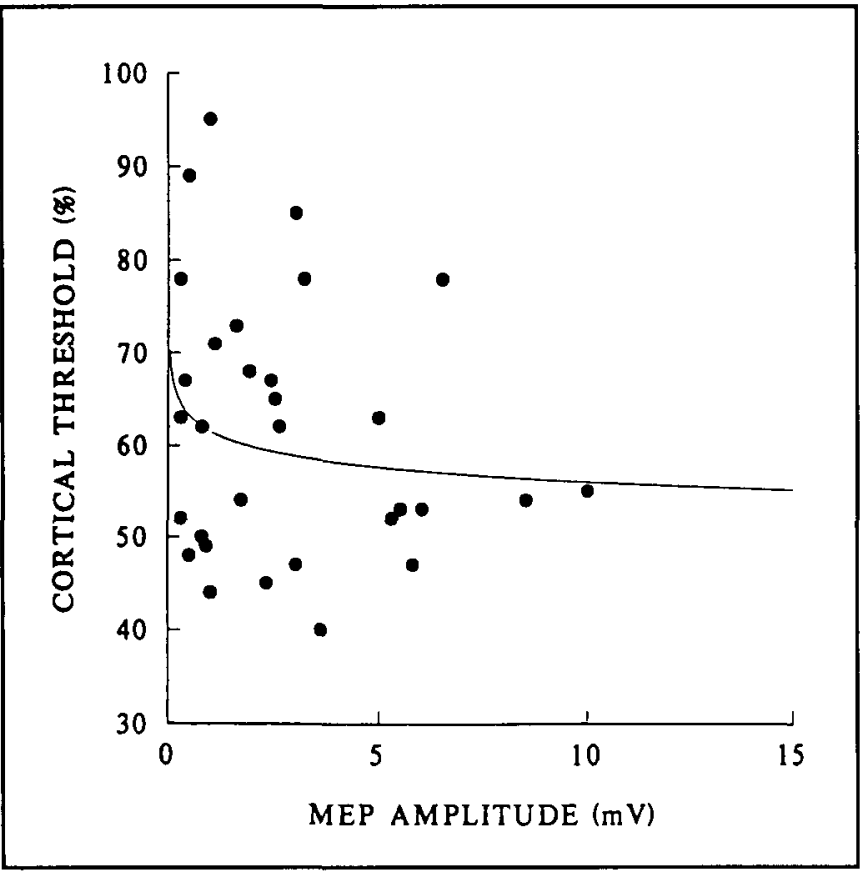

Figure 3 - ALS patients. Lack of any meaningful correlation between MEP amplitude and cortical threshold.

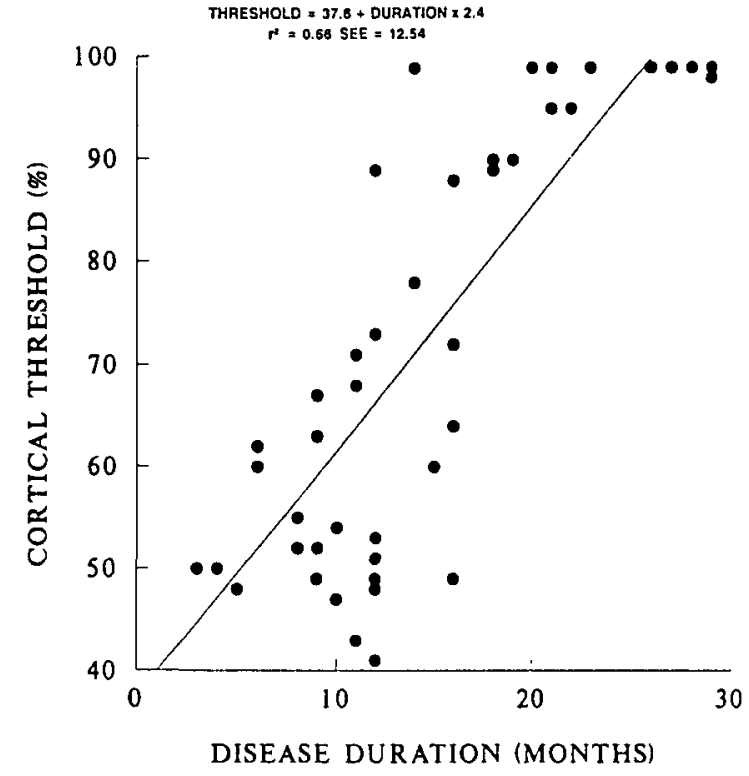

Figure 4 - Relation between cortical threshold and disease duration in $A L S$ is linear $\left(r^{2}=0.66\right)$. Nine points are shown at values for cortical threshold $=99$; these are patients in whom no response was obtained. Their values were not used in calculating the regression coefficients. 
correlation between threshold and MEP amplitude (Figure 3).

The mean cortical threshold for normal hand muscles $(54.8 \%)$ and its narrow range is similar to other recent reports. ${ }^{23.25}$ Threshold is age-dependent, and is high in infants, falling to adult values by the second decade of life. ${ }^{32}$ The protracted time for cortical threshold to fall to adult values compared to the attainment of adult central motor conduction velocities reflects slow maturation of corticomoneuronal connections. ${ }^{32}$ One might have anticipated that in ALS, a disease that affects the corticomotoneuronal system, cortical threshold would be uniformly raised. This was not the case; many patients had values in the normal range for aged matched controls and a few had low values. Although values for different individuals varied considerably there was a striking and significant exponential relationship between threshold and MEP/CMAP ratio and linear relationship between threshold and disease duration.

Given the normal amplitude CMAP in the majority of patients and the lack of active denervation (fibrillation or positive sharp waves) in the target muscle, it can be reasonably assumed that motor neuron pool was sufficiently adequate to preclude it as a likely cause of increased cortical threshold in the majority of our patients. In support of this we have noted that in postpoliomyelitis syndrome cortical threshold is normal even when the MEP is of small amplitude and recorded from quite severely wasted muscles (unpublished data). Therefore, corticomotoneuronal death or dysfunction is the most likely cause for the increasing cortical threshold that occurs as ALS progresses. It is possible that dendritic thinning, which has been identified as an early feature of the disease ${ }^{33}$ is responsible for the timerelated rise in cortical threshold.

Paradoxically normal, or low thresholds, which have been previously observed in $\mathrm{ALS},{ }^{24}$ may also result from the effect of voluntary muscle contraction. ${ }^{34-36}$ This was carefully avoided during stimulation. Caramia et al..$^{24}$ noted that fasciculation was present in the muscles from which low or normal threshold MEPs were recorded. They argued that the hyperexcitability of the anterior horn cells, which might account for some fasciculation in ALS, would equally make them more receptive to the descending cortical volleys. We could not confirm that patients with prominent fasciculations were necessarily those with normal or low cortical thresholds. About half the number of target muscles were not fasciculating and even in those patients with fasciculations, threshold measurements were only accepted when the MEP was elicited during a fasciculation-free period. In some of the patients with marked fasciculation it was not possible to elicit a MEP.

Another plausible explanation for the ready excitability of the motor cortex in ALS lies in glutamate excitotoxicity. There has been much recent interest in the amino-acid, excitotoxic pathogenesis of ALS; specifically as it relates to glutamate transmission. ${ }^{37}$ Glutamate is the putative transmitter of the corticomotoneuronal system that stimulates lower motor neurons ${ }^{38}$ and disturbed function of the NMDA receptor in the motor cortex and spinal cord may be implicated in neuronal death in ALS. NMDA receptors are distributed throughout the spinal grey matter of the human spinal cord with foci of high density binding sites corresponding in distribution to the anterior horn cells ${ }^{39}$ and glutamate dehydrogenase is elevated and transmitter aminoacids (glutamate and aspartate) are reduced in the same regions of the spinal cord in patients dying with ALS. ${ }^{40}$ Recent studies have shown a defect in high-affinity glutamate transport, with a $70 \%$ reduction in ALS motor cortex. Faulty transport probably induces toxic and pathogenic levels of extracellular glutamate. $^{41}$

If disordered glutamate metabolism, or some other excitotoxic aminoacid, is responsible for lowering the threshold to cortical magnetic stimulation it might be anticipated that with disease progression, as corticomotoneurons are "excited to death", threshold will rise and eventually the corticomotoneurons will become inexcitable. The results depicted in Figure 4 , which show a linear correlation between cortical threshold and disease duration, support this concept.

In conclusion we have shown that early in the course of ALS, cortical threshold, which correlated with the MEP/CMAP ratio, was paradoxically normal and as the disease progressed there was an exponential rise in threshold associated with a fall in the MEP/CMAP ratio. This series of events, which might reflect glutamate-induced corticomotoneuronal excitotoxicity, partially support the concept that ALS may primarily be a disease of the corticomotoneuron.

\section{ACKNOWLEDGEMENTS}

Supported by grants from the Medical Research Council of Canada (PG-11127) and the British Columbia Health Care Research Foundation (85-91-2).

\section{REFERENCES}

1. Amassian VE, Steward M. Quick GJ, Rosenthal JC. Physiological basis of motor effects of a transient stimulus 10 cerebral cortex. Neurosurgery 1987; 20: 74-93.

2. Day BL, Dressler D, Maertens de Noordhout A, Marsden CD, et all. Electrical and magnetic stimulation of the human motor cortex: surface EMG and single motor unit responses. J Physiol (Lond) 1989; 412: 449-473.

3. Edgley SA, Eyre JA, Lemon RN, Miller S. Excitation of the corticospinal tract by electromagnetic and electrical stimulation of the scalp in the macaque monkey. J Physiol (Lond) 1990; 425: 301-320.

4. Porter R. The cortico-motoneuronal component of the pyramidal tract: corticomotoneuronal connections and functions in primates. Brain Res Rev 1985; 357: 1-26.

5. Porter R. The corticomotoneuronal projections: synaptic events related to skilled movement. Proc Roy Soc Lond (Biol) 1987; 231: 147-168.

6. Phillips CG, Porter R. Corticospinal Motoneurons. Academic Press, New York, 1977.

7. Davidoff RA. The pyramidal tract. Neurology 1990; 40:332-339.

8. Iwatsubo T, Kuzuhara S, Kanemitsu A, et al. Corticofugal projections to the motor nuclei of the brainstem and spinal cord in humans. Neurology 1990; 40:309-312.

9. Sillevis Smitt PAE, de Jong JMBV. Animal models of amyotrophic lateral sclerosis and spinal muscular atrophy. J Neurol Sci 1989; 91: 231-258.

10. Eisen A, Kim S, Pant B. Amyotrophic lateral sclerosis (ALS): a phylogenetic disease of the corticomotoneuron? Muscle Nerve 1992; 15: 219-228.

11. Eisen A, Calne DB. Amyotrophic lateral sclerosis, Parkinson's disease and Alzheimer's disease: phylogenetic disorders of the human neocortex sharing many characteristics. Can J Neurol Sci 1992; 19 (Suppl): 117-120.

12. Charcot JM. Clinical Lectures on Diseases of the Nervous System. Vol. III (translated by Savill T), The New Sydenham Society, London, 1889: 164-182.

13. Keirnahan JA, Hudson AJ. Changes in sizes of cortical and lower motor neurons in amyotrophic lateral sclerosis. Brain 1991; 114: 843-853. 
14. Cheney PD, Fetz EE. Comparable patterns of muscle facilitation evoked by individual corticomotoneuronal (CM) cells and by single intracortical microstimuli in primates: evidence of functional groups of CM cells. J Neurophysiol 1985; 53: 786-804.

15. Humphrey DR. Representation of movements and muscles within the primate precentral motor cortex: historical and current perspectives. Fed Proc 1986; 45: 2687-2699.

16. Wiesendanger $M$. Output organization of the rolandic cortex as revealed by electrical stimulation. In: Rossini PM, Marsden CD, eds. Non-Invasive Stimulation of Brain and Spinal Cord: Fundamentals and Clinical Applications. New York: Alan R. Liss, Inc 1988; 23-35.

17. Homberg V, Stephan KM, Netz J. Transcranial stimulation of motor cortex in upper motor neuron syndrome: its relation to motor deficit. Electroencephalogr Clin Neurophysiol 1991; 81: 377388.

18. Rowland LP. Ten central themes in a decade of ALS research. In: Rowland LP, ed. Advances in Neurology, Vol. 56: Amyotrophic Lateral Sclerosis and Other Motor Neuron Diseases. Raven Press Lid., 1991: 3-23.

19. Parry GJ, Clarke S. Multifocal acquired demyelinating neuropathy masquerading as motor neuron disease. Muscle Nerve 1988; 11 : 103-107.

20. Pestronk A. Invited review: motor neuronopathies, motor neuron disorders, and antiglycolipid antibodies. Muscle Nerve 1991; 14: 927-936.

21. Daube JR. Electrophysiolgical studies in the diagnosis and prognosis of motor neuron diseases. Neurol Clin 1985; 3: 473-493.

22. Eisen A, Shtybel W. Clinical experience with transcranial magnetic stimulation. Muscle Nerve 1990; 13: 995-1011.

23. Hufnagel A, Elger CE, Marx W, Ising A. Magnetic stimulation motor-evoked potentials in epilepsy: effects of the disease and anticonvulsant medications. Ann Neurol 1990; 28: 680-686.

24. Caramia MD, Cicinelli P, Paradiso C, Marioenzi R, et al. Excitability changes of muscular responses to magnetic brain stimulation in patients with central motor disorders. Electroencephalogr Clin Neurophysiol 1991; 81: 243-250.

25. Wassermann EM, McSahane LM, Hallett M, Cohen LG. Noninvasive mapping of muscle representations in human motor cortex. Electroencephalogr Clin Neurophysiol 1992; 85: 1-8.

26. Hugon J, Lubeau M, Tabarard F, Chazot F, Vallat JM, et al. Central molor conduction in motor neuron disease. Ann Neurol 1987; 22: 544-546.

27. Ingram DA, Swash M. Central motor conduction is abnormal in motor neuron disease. J Neurol Neurosurg Psychiatry 1987; 50: 159-166.

28. Schriefer TN, Hess CW, Mills KR, Murray NM. Central motor conduction studies in motor neuron disease using magnetic brain stimulation. Electroencephalogr Clin Neurophysiol 1989; 74: $431-437$.

29. Eisen A, Shytbel W, Murphy K, Hoirch M. Cortical magnetic stimulation in amyotrophic lateral sclerosis. Muscle Nerve 1990; 13: 146-151.

30. Berardelli A, Inghilleri M, Cruccu G, Mercuri B, Manfredi M. Electrical and magnetic transcranial stimulation in patients with corticospinal damage due to stroke or motor neuron disease. Electroencephalogr Clin Neurophysiol 1991; 81: 389-396.

31. Day BL, Rothwell JC, Thompson PD, Dick JP, Cowan JMA, et al. 2. Multiple descending volleys. Brain 1987; 110: 1191-1209.

32. Muller K, Homberg V, Lenard HG. Magnetic stimulation of motor cortex and nerve roots in children. Maturation of corticomotoneuronal projections. Electroencephalogr Clin Neurophysiol 1991; 81: 63-70.

33. Carpenter S, Karpati G, Durham H. Dendritic attrition precedes motor neuron death in amyotrophic lateral sclerosis (ALS). Neurology 1988; 38 (Suppl): 252.

34. Hess CW, Mills KR, Murray NMF. Magnetic stimulation of the human brain: facilitation of motor responses by voluntary contraction of ipsilateral and contralateral muscles with additional observations in an amputee. Neurosci Lett 1986; 71: 235-240.

35. Rothwell JC, Thompson PD, Day BL, Dick JPR, Kachi T, et al. Motor cortical stimulation in intact man. 1. General characteristics of EMG responses in different muscles. Brain 1987; 110; 1173-1190.

36. Thompson PD, Day BL, Rothwell JC, Dressler D, Maertens de Noordhout A, et al. Further observation on the facilitation of muscle responses to cortical stimulation by voluntary contraction. Electroencephalogr Clin Neurophysiol 1991; 81:397-402.

37. Plaitakis A. Glutamate dysfunction and selective motor neuron degeneration in amyotrophic lateral sclerosis: a hypothesis. Ann Neurol 1990; 28: 3-8.

38. Young AB, Penney JB, Dauth GW, et al. Glutamate or aspartate as a possible neurotransmitter of cerebral corticofugal fibers in the monkey. Neurology 1983; 33: 1513-1516.

39. Shaw $\mathrm{PJ}$, Ince $\mathrm{PG}$, Johnson $M$, Perry EK, Candy J. The quantitative autoradiographic distribution of $\left[{ }^{3} \mathrm{H}\right] \mathrm{MK}-801$ binding sites in normal human spinal cord. Brain Res 1991; 539: 164-168.

40. Malessa S, Leigh PN, Bertel O, Sluga E, Hornykeiwicz O. Amyotrophic lateral sclerosis: glutamate dehydrogenase and transmitter amino acids in the spinal cord. J Neurol Neurosurg Psychiatry 1991; 54: 984-988.

41. Rothstein JD, Martin LJ, Kuncl RW. Decreased glutamate transport by the brain and spinal cord in amyotrophic lateral sclerosis. $\mathrm{N}$ Engl J Med 1992; 326: 1464-1468. 